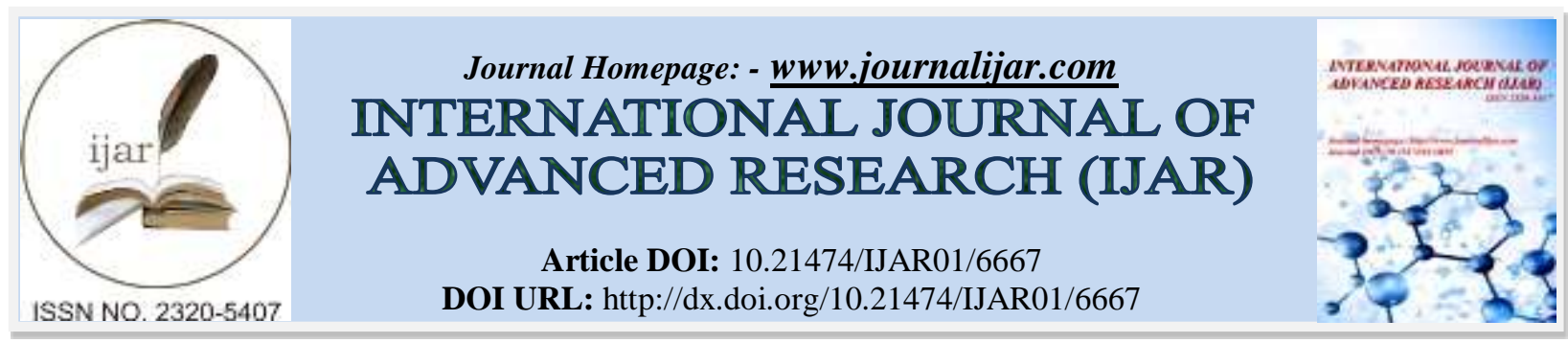

RESEARCH ARTICLE

\title{
EVALUATION OF PEGUERO-LO PRESTI CRITERIA FOR ASSESSMENT OF LEFT VENTRICULAR HYPERTROPHY.
}

\section{Dr. Suresh V Patted, Dr. Sanjay C Porwal, Dr. Sameer S Ambar, Dr. M R Prasad, Dr. Akshay S Chincholi,} Dr. Vishwanath Hesarur and Dr. Vaibhav Patil.

\section{Manuscript Info}

Manuscript History

Received: 04 January 2018

Final Accepted: 06 February 2018

Published: March 2018

Keywords:-

Cornell voltage criteria; Left ventricular hypertrophy; Peguro-lo-presti criteria;

Sokolow-Lyon criteria.

\section{Abstract}

Background and objectives: The sensitivity of ECG to diagnose LVH by Peguero-Lo Presti criteria has shown higher sensitivity when compared to well established criterion like Cornell voltage and Sokolow Lyon criteria. This study was aimed to find the accuracy of Peguero Lo Presti criteria in the diagnosis of LVH in patients with hypertension.

Methodology: This one cross-sectional study was conducted in the Department of Cardiology of a tertiary care centre in North Karnataka from May 2017 to October 2017. A total of 400 patients with age $>30$ years having hypertension were studied. All the patients were subjected to ECG and 2D echo.

Results: In this study majority $(73.5 \%)$ of the patients were males and male to female ratio was 2.77:1. Most of the patients were aged between 61 to 70 years $(38.50 \%)$ and the mean age was $63.79 \pm 10.36$ years. Based on 2D echocardiography, LVH was diagnosed in $48 \%$ of the patients. Based on, Peguro-lo-presti, Cornell Voltage and SokolowLyon criteria $30.50 \%, 24.50 \%$ and $21 \%$ of the patients were diagnosed to have LVH respectively. Of the 192 patients, one hundred and four (104) patients were diagnosed to have LVH based on Peguro-lo-presti criteria with strong agreement $(\mathrm{p}<0.001)$ between Peguro-lo-presti criteria and 2D echocardiograpgy for the diagnosis of LVH with sensitivity of 54.17\%. Also using Cornell Voltage criteria 76 out of 192 were diagnosed to have LVH and the sensitivity was $39.58 \%$ and using Sokolow-Lyon criteria, 56 out of 192 were diagnosed to have LVH with sensitivity of $29.17 \%$. The Peguero-Lo Presti ECG criteria yielded higher sensitivity $(54.17 \%)$ and specificity $(91.35 \%)$ in the diagnosis of LVH in patients with hypertension.

Conclusion: Peguero-Lo Presti criteria has higher sensitivity and specificity in the ECG diagnosis of LVH compared to Sokolow-Lyon and Cornell voltage criteria considering LV mass index by 2D Echocardiography as reference standard.

Copy Right, IJAR, 2018,. All rights reserved.

\section{Introduction: -}

Left ventricular hypertrophy is a marker of subclinical cardiac disease and helps in prognostication. It is a common finding in patients with hypertension and can be diagnosed either by electrocardiography or by echocardiography. ${ }^{1}$

Corresponding Author:- Dr. Sanjay C Porwal. 
Population based studies have shown a strong association between hypertension and LVH. In fact in severe forms of hypertension there is a $>50 \%$ incidence of $\mathrm{LVH}$ while in milder forms it is $<25 \%$. ${ }^{2}$ The Framingham studies have also established an age linked prevalence of $\mathrm{LVH}^{3}$

Left ventricular hypertrophy (LVH) secondary to arterial hypertension is a complex cardiac phenotype resulting from the response of myocyte and non-myocyte components to mechanical and neuro-humoral stimuli. ${ }^{4}$

Various studies have shown that LVH independently predicts morbidity and mortality. LVH predisposes to heart failure, ventricular tachyarrhythmia, atrial fibrillation, ischemic stroke, embolic stroke and sudden cardiac death. ${ }^{5}$

The sensitivity of all the well-established ECG criteria to diagnose LVH is low and is in the range of 7-35\% with mild LVH and only $10-50 \%$ with moderate to severe LVH whereas the overall specificity is $>90 \%$. $^{6}$

To improve the sensitivity of ECG to diagnose LVH we evaluated the novel Peguero-Lo Presti criteria which has shown higher sensitivity when compared to older well established criterion like Cornell voltage and Sokolow Lyon criteria

\section{Materials and Methods:-}

This one cross-sectional study was conducted in the Department of Cardiology of a tertiary care centre in North Karnataka from May 2017 to December 2017. Prior to the commencement of the study, ethical clearance was obtained from Human Ethics Committee.

A total of 400 patients aged above 30 years presenting with hypertension to the cardiology OPD who underwent ECG and 2D echocardiography were included in the study. Patients with myocardial infarction, valvular heart disease (Grade II or higher), valvular stenosis, LV dysfunction, pericardial disease, COPD, bundle branch blocks, atrial fibrillation or flutter were excluded from the study. The patients fulfilling selection criteria were informed in detail about the nature of the study and a written informed consent was obtained before enrolment.

Detailed history was obtained and thorough clinical examination was done and the findings were recorded on a predesigned and pretested proforma. All the patients underwent ECG and 2D echocardiography.

\section{D echocardiography:-}

Transthoracic echocardiography was used as a method of reference to estimate left ventricular mass. ${ }^{7}$ All echocardiograms were recorded by a cardiologist. The LV was visualised with the patient lying in a modified left lateral decubitus position, with the ultrasound probe at the left parasternal window angled to visualise the heart in the long axis view. All the M-mode and 2D measurements were performed by the leading-edge-to-leading edge method, as described by the American Society of Echocardiography (ASE).

Left ventricular end-diastolic and end-systolic measurements were obtained with the patient in a partial left lateral decubitus position according to recommendations by the American Society of Echocardiography. ${ }^{89}$ Frames with optimal visualization of interfaces and showing simultaneous visualization of the septum, left ventricular internal diameter, and posterior wall were used. Left ventricular mass was calculated by using the Devereux formula: left ventricular mass (g) 1/4 $0.80 \_\{1.04 \ldots \text { [(septal thickness } p \text { internal diameter } p \text { posterior wall thickness) } 3 \text { - (internal }$ diameter)3] \} b $0.6 \mathrm{~g}$. The left ventricular mass was indexed according to body surface area. LVH was defined as a left ventricular mass index $>115 \mathrm{~g} / \mathrm{m}^{2}$ in male subjects and $>95 \mathrm{~g} / \mathrm{m} 2$ in female subjects. ${ }^{10}$

\section{ECG criterion:-}

A single electrocardiogram for every patient was obtained on the same day the echocardiogram was obtained. All 12-lead ECG interpretations were independently reviewed. Individual leads were analyzed by measuring the tallest $\mathrm{R}$ and the deepest $\mathrm{S}$ or QS complex in all the precordial and limb leads using the PR segment as baseline. In cases of voltage differences within the same lead, only the largest complex was selected. The Peguero-Lo Presti criteria was obtained by adding SD to the S amplitude in V4 (SD + SV4). Cutoff values of SD + SV4 $\geq 2.3 \mathrm{mV}$ for female subjects and $\geq 2.8 \mathrm{mV}$ for male subjects were considered positive for LVH based on the recent study by Peguero JG et al. In cases in which the SD was found in lead V4, the S wave amplitude was doubled to obtain the value SD + SV4. 
The Cornell voltage criteria was used as the main comparison given its reputation as the most accurate of the reported measurements. ${ }^{11}$ The sex-specific Cornell voltage criteria was computed as the amplitude of R in aVL plus the amplitude of S or QS complex in V3 $(\mathrm{RaVL}+\mathrm{SV} 3)$ with a cutoff of $>2.8 \mathrm{mV}$ in men and $>2.0 \mathrm{mV}$ in women. ${ }^{12}$

The Sokolow-Lyon voltage was obtained by adding the amplitude of S in V1 and the amplitude of R in V5 or V6 $\geq$ $3.5 \mathrm{mV}\left(\mathrm{SV} 1+\mathrm{RV} 5\right.$ or RV6); ${ }^{13,14}$

\section{Statistical analysis:-}

The categorical data was expressed as rates, ratios and percentages and comparison was done using chi-square test. Continuous data was expressed as mean \pm standard deviation. The agreement between ECG criteria and $2 \mathrm{~d}$ echocardiography was analysed with McNemar's test and a 'p' value of less than or equal to 0.05 was considered as statistically significant. The accuracy of Peguero-Lo Presti criteria for the assessment of LVH was determined by estimating sensitivity, specificity, positive predictive value and negative predictive value.

\section{Results:-}

In this study $73.5 \%$ of the patients were males with male to female ratio of 2.77:1 (Graph 1). Age ranged between 35 to 89 years and most of the patients were aged between 61 to 70 years $(38.50 \%)$ and the mean age was $63.79 \pm 10.36$ years (Table 2 and 3). The clinical profile of the study population that is mean height, weight, ECG and 2D echocardiography parameters are as shown in table 3. Based on 2D echocardiography, LVH was diagnosed in 48\% of the patients (Graph 2). Based on ECG criteria that is, Peguero-Lo Presti, Cornell Voltage and Sokolow-Lyon criteria $30.50 \%, 24.50 \%$ and $21 \%$ of the patients were diagnosed to have LVH respectively (Table 3).

Out of 192 patients with LVH based on 2D echocardiography, 104 were diagnosed to have LVH based on PegueroLo Presti criteria with strong agreement $(\mathrm{p}<0.001)$ between Peguero-Lo Presti criteria and 2D echocardiography for the diagnosis of LVH with sensitivity of 54.17\%. Likewise, based on Cornell Voltage criteria 76 out of 192 were diagnosed to have LVH with sensitivity of $39.58 \%$ while based on Sokolow-Lyon criteria, 56 out of 192 were diagnosed to have LVH with sensitivity of $29.17 \%$. The Peguero-Lo Presti ECG criteria yielded higher sensitivity $(54.17 \%)$ and specificity $(91.35 \%)$ in the diagnosis of LVH in patients with hypertension (Table 4).

\section{Discussion:-}

The present study showed that, Peguero-Lo Presti criteria has higher sensitivity (54.17\%), while maintaining higher specificity $(91.35 \%)$ with higher diagnostic accuracy $(73.50 \%)$ in the diagnosis of LVH among the patients with hypertension compared to the other two criterions that is Sokolow-Lyon criteria and Cornell Voltage criteria (Table $5)$.

The Sokolow-Lyon criteria ${ }^{14}$ has been evaluated in various studies to give sensitivity of $32 \%,{ }^{14} 33 \%,{ }^{14} 43 \%$, ${ }^{15}$ wile in this study the sensitivity was $29.17 \%$ which was in agreement with the previous studies. The Cornell voltage criteria has been evaluated to give sensitivity of $41 \%,{ }^{16}$ and $28 \%{ }^{14}$ which was found to be $39.58 \%$ in the present study.

A retrospective study by Peguero JG et al. ${ }^{17}$ in 2017 which devised the Peguero-Lo Presti criteria also reported sensitivity of $62 \%$ with specificity of $90 \%$ with strong agreement $(\mathrm{p}<0.011)$. The cut-off values determined by ROC obtained were $\geq 2.3 \mathrm{mV}$ for females and $\geq 2.8 \mathrm{mv}$ for males. In this study we used the same cut off values as that of Peguero JG et al. ${ }^{17}$ and found higher sensitivity and specificity compared to other two criterions viz. Sokolow-Lyon and Cornell voltage criteria. ${ }^{14}$

LVH is mainly determined by an increase in left ventricular mass, which can be estimated by the electrical voltage changes detected on the surface electrocardiogram. This principle makes the electrocardiogram an acceptable surrogate to detect changes in left ventricular mass. ${ }^{17}$

The SD was the best single lead predictor of LVH in the studied cohorts. In fact, the sum of SD + SV4 in the studied population had a better diagnostic performance and showed nominally an improved performance over the traditional LVH. $^{17}$ 
However, the cardiac electrical voltage does not exclusively depend on the amount of myocardium. But, it is dependent on active and passive electrical properties of the heart and torsum. These in turn are modified by influencing factors such as distance of left ventricular cavity-electrode, the location of the surface electrode, individual antrophometric differences, conduction abnormalities, fibrosis of the myocardium, and lung pathology ${ }^{18,19}$ In addition, it has been described that the ECG voltage may vary significantly from day to day, between patients, or even within the same patient. ${ }^{13,20}$ All of these factors may attenuate the reproducibility of the test, leading to diagnostic errors. Given the aformentioned pitfalls, measurement of the maximum voltage increase in any single lead would be more sensitive in identifying an increase in the ventricular mass, rather than using any fixed lead criteria.

Overall the present study showed that, Peguero-Lo Presti criteria ${ }^{17}$ has higher sensitivity and specificity in the ECG diagnosis of LVH compared to Sokolow-Lyon ${ }^{14}$ and Cornell voltage criteria considering LV mass index by 2D Echocardiography as reference standard. However, these observations require further validation due to the potential limitations of this study that it is a single centre study and relatively smaller sample size. Another limitation is that the left ventricular mass and left ventricular mass index were estimated by using two-dimensional echocardiography and the main determinant of LVH in this study was the left ventricular mass. Though, echocardiography is known to have good reproducibility for the diagnosis of LVH and remains the most frequently used method in clinical practice. ${ }^{21}$ It is reported that, $2 \mathrm{D}$ echocardiography ignores the hypertrophic rebuilding of myocardial tissue that occurs in early stages and may contribute to the discrepancies. ${ }^{22,23}$

\section{Graph 1. Distribution of patients according to the sex}

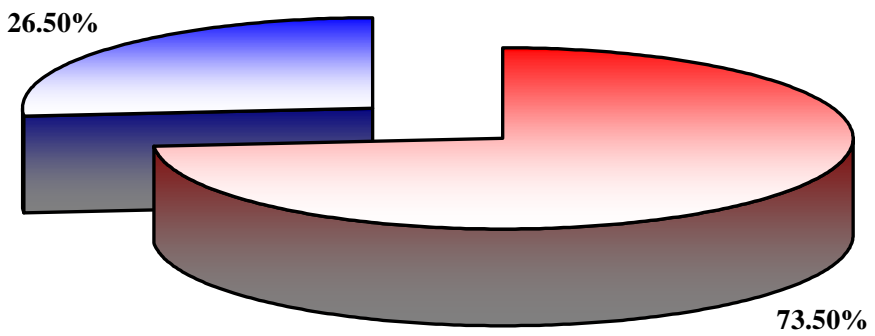

$\square$ Male $\square$ Female 


\section{Graph 2. Distribution of patients according to the diagnosis of $\mathrm{LVH}$ based on $\mathrm{LV}$ mass index}
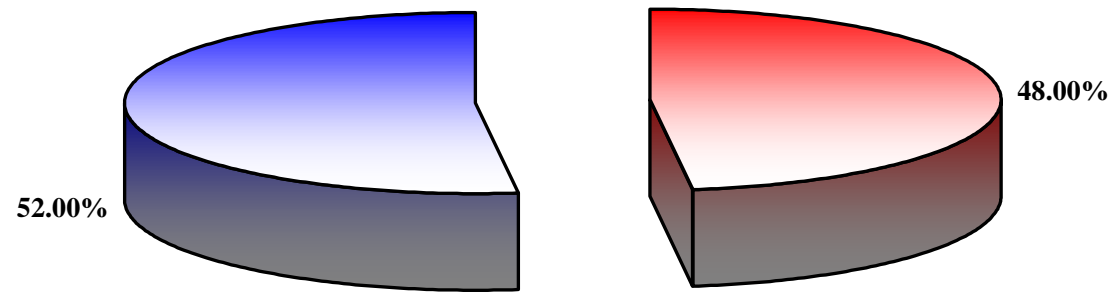

\section{Yes $\square$ No}

Table 1:- Distribution of patients according to the age

\begin{tabular}{|l|l|l|}
\hline \multirow{2}{*}{ Age (Years) } & Distribution $(\mathbf{n}=\mathbf{4 0 0})$ \\
\cline { 2 - 3 } & Number & Percentage \\
\hline 30 or less & 0 & 0.00 \\
\hline 31 to 40 & 6 & 1.50 \\
\hline 41 to 50 & 36 & 9.00 \\
\hline 51 to 60 & 110 & 27.50 \\
\hline 61 to 70 & 154 & 38.50 \\
\hline 71 to 80 & 66 & 16.50 \\
\hline 81 to 90 & 28 & 7.00 \\
\hline 91 to 100 & 0 & 0.00 \\
\hline Total & $\mathbf{4 0 0}$ & $\mathbf{1 0 0 . 0 0}$ \\
\hline
\end{tabular}

Table 2:- Clinical profile of the study population

\begin{tabular}{|l|l|l|l|l|l|}
\hline \multirow{2}{*}{ Variables } & \multicolumn{2}{l}{ Distribution $(\mathbf{n}=\mathbf{4 0 0})$} & \multirow{2}{*}{ Median } & Range \\
\cline { 2 - 3 } & Number & Percentage & & Minimum & Maximum \\
\hline Age (Years) & 63.79 & 10.36 & 63.50 & 35.00 & 89.00 \\
\hline Height (cms) & 160.36 & 4.35 & 160.00 & 150.00 & 170.00 \\
\hline Weight (Kg) & 63.21 & 6.31 & 62.00 & 51.00 & 84.00 \\
\hline Body Surface Area & 1.67 & 0.10 & 1.64 & 1.44 & 1.99 \\
\hline Duration of Hypertension (Years) & 7.78 & 6.62 & 7.00 & 0.08 & 76.00 \\
\hline Systolic blood pressure (mmHg) & 143.49 & 17.20 & 140.00 & 110.00 & 200.00 \\
\hline Diastolic blood pressure (mmHg) & 86.43 & 8.11 & 90.00 & 70.00 & 110.00 \\
\hline Pulse rate (/Minute) & 81.78 & 8.85 & 82.00 & 60.00 & 110.00 \\
\hline LVIDd & 4.13 & 0.35 & 4.10 & 3.20 & 4.90 \\
\hline PWTd & 1.25 & 0.12 & 1.25 & 1.00 & 1.50 \\
\hline IVSd & 1.31 & 0.15 & 1.30 & 0.50 & 1.60 \\
\hline LV mass by 2D & 193.63 & 39.65 & 189.50 & 97.00 & 283.00 \\
\hline LV mass Index & 115.98 & 25.06 & 113.00 & 59.00 & 172.00 \\
\hline SD & 1.48 & 0.34 & 1.40 & 1.00 & 2.60 \\
\hline SV4 & 0.97 & 0.25 & 0.90 & 0.10 & 1.60 \\
\hline
\end{tabular}




\begin{tabular}{|l|l|l|l|l|l|}
\hline SD + SV4 & 2.45 & 0.44 & 2.50 & 1.50 & 3.50 \\
\hline RaVL & 1.34 & 0.37 & 1.30 & 0.60 & 2.50 \\
\hline SV3 & 1.02 & 0.25 & 1.00 & 0.60 & 1.80 \\
\hline RaVL + SV3 & 2.36 & 0.47 & 2.30 & 1.50 & 3.40 \\
\hline SV1 & 1.20 & 0.28 & 1.20 & 0.60 & 2.00 \\
\hline RV5 or RV6 & 1.76 & 0.41 & 1.70 & 0.70 & 3.10 \\
\hline SV1 + RV5 or RV6 & 2.96 & 0.55 & 2.90 & 1.40 & 4.20 \\
\hline
\end{tabular}

Table 3:- Distribution of patients according to the diagnosis based on Peguero-Lo Presti criteria

\begin{tabular}{|l|l|l|l|}
\hline \multirow{2}{*}{ ECG criteria } & Findings & \multicolumn{2}{l|}{ Distribution (n=400) } \\
\cline { 3 - 4 } & & Number & Percentage \\
\hline Peguero-Lo Presti criteria & Yes (Raised SD + SV4) & 122 & 30.50 \\
\hline & No (Normal SD + SV4) & 278 & 69.50 \\
\hline Cornell Voltage criteria for LVH & Total & $\mathbf{4 0 0}$ & $\mathbf{1 0 0 . 0 0}$ \\
\hline & Yes (Raised RaVL + SV3) & 98 & 24.50 \\
\hline & No (Normal RaVL + SV3) & 302 & 75.50 \\
\hline Sokolow-Lyon criteria for LVH & Total & $\mathbf{4 0 0}$ & $\mathbf{1 0 0 . 0 0}$ \\
\hline & Yes (Raised SV1 + RV5 or RV6) & 84 & 21.00 \\
\hline & No (Normal SV1 + RV5 or RV6) & 316 & 79.00 \\
\hline & Total & $\mathbf{4 0 0}$ & $\mathbf{1 0 0 . 0 0}$ \\
\hline
\end{tabular}

Table 4:- Accuracy of ECG criteria in predicting LVH considering LV mass index as gold standard

\begin{tabular}{|c|c|c|c|c|c|c|c|c|c|}
\hline \multirow{2}{*}{$\bigcup_{\text {U }}$} & \multirow[b]{2}{*}{ 记 } & \multicolumn{2}{|c|}{ Coronary angiography findings } & \multirow[b]{2}{*}{$\stackrel{\bar{\sigma}}{\stackrel{\pi}{\theta}}$} & \multirow[b]{2}{*}{ 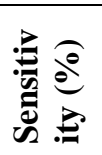 } & \multirow{2}{*}{ 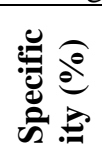 } & \multirow[b]{2}{*}{20} & \multirow[b]{2}{*}{$\bar{z} \sqrt{e}$} & \multirow[b]{2}{*}{ 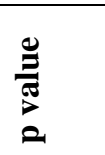 } \\
\hline & & Yes & No & & & & & & \\
\hline \multirow{3}{*}{$\begin{array}{l}\text { Peguero-Lo } \\
\text { Presti } \\
\text { criteria }\end{array}$} & Yes & 104 & 18 & 122 & 54.17 & 91.35 & 85.25 & 68.35 & $<0.001$ \\
\hline & No & 88 & 190 & 278 & & & & & \\
\hline & Total & 192 & 208 & 400 & & & & & \\
\hline \multirow{3}{*}{$\begin{array}{l}\text { Cornell } \\
\text { Voltage } \\
\text { criteria }\end{array}$} & Yes & 76 & 22 & 98 & 39.58 & 89.42 & 77.55 & 61.59 & $<0.001$ \\
\hline & No & 116 & 186 & 302 & & & & & \\
\hline & Total & 192 & 208 & 400 & & & & & \\
\hline \multirow{3}{*}{$\begin{array}{l}\text { Sokolow- } \\
\text { Lyon } \\
\text { criteria }\end{array}$} & Yes & 56 & 28 & 84 & 29.17 & 86.54 & 66.67 & 56.96 & $<0.001$ \\
\hline & No & 136 & 180 & 316 & & & & & \\
\hline & Total & 192 & 208 & 400 & & & & & \\
\hline
\end{tabular}

Table 5:- Comparison of accuracy of ECG criterion in predicting LVH considering LV mass index as gold standard

\begin{tabular}{|l|l|l|l|l|l|}
\hline Criterion & Sensitivity & Specificity & PPV & NPV & Diagnostic accuracy \\
\hline Peguero-Lo Presti criteria & 54.17 & 91.35 & 85.25 & 68.35 & 73.5 \\
\hline Cornell Voltage criteria & 39.58 & 89.42 & 77.55 & 61.59 & 65.50 \\
\hline Sokolow-Lyon criteria & 29.17 & 86.54 & 66.67 & 56.96 & 59.00 \\
\hline
\end{tabular}

\section{References:-}

1. Elias MF, Sullivan LM, Elias PK, D'Agostino RB, Wolf PA, Seshadri S, et al. Left ventricular mass, blood pressure, and lowered cognitive performance in the Framingham offspring. Hypertension 2007; 49:439-45.

2. Post WS, Larson MG, Levy D. Impact of left ventricular structure on the incidence of hypertension: the Framingham Heart Study. Circulation 1994;90:179-85.

3. Hammond IW, Devereux RB, Alderman MH, Lutas EM, Spitzer MC, Crowley JS, et al - The prevalence and correlates of echocardiographic left ventricular hypertrophy among employed patients with uncomplicated hypertension. J Am Coll Cardiol $1986 ; 7: 639-650$

4. C Diez J, Frohlich E. A translational approach to hypertensive heart disease. Hypertension 2010; 55: 1-8.

5. Mann DL, Bonow RO, Zipes DP, Braunwald E, Libby P. Braunwalds Heart Disease - A textbook of cardiovascular medicine $10^{\text {th }}$ ed., New Delhi; Saunders; 2015. 
6. Barrios V, Escobar C, Calderon A, Ribas L, Marti D, Asin E. Prevalence of left ventricular hypertrophy detected by Cornell voltage-duration product in a hypertensive population. Blood Press 2008;17:110-5.

7. Bacharova L, Ugander M. Left ventricular hypertrophy: the relationship between the electrocardiogram and cardiovascular magnetic resonance imaging. Ann Non-invasive Electrocardiol 2014;19:524-33.

8. Nagueh SF, Smiseth OA, Appleton CP, Byrd BF, Dokainish H, Edvardsen T, et al. Recommendations for the evaluation of left ventricular diastolic function by echocardiography: an update from the American Society of Echocardiography and the European Association of Cardiovascular Imaging. J Am Soc Echocardiogr 2016;29:277-314.

9. Sahn D, De Maria A, Kisslo J, Weyman A. Recommendations regarding quantitation in M-mode echocardiography: results of a survey of echocardiographic measurements. Circulation 1978;58:1072-83.

10. Recommendations for Cardiac Chamber Quantification by Echocardiography in Adults: An Update from the American Society of Echocardiography and the European Association of, Cardiovascular Imaging. Eur Heart J Cardiovasc Imaging 2016;17(4):412.

11. Schillaci G, Verdecchia P, Borgioni C, Ciucci A, Guerrieri M, Zampi I, et al. Improved electrocardiographic diagnosis of left ventricular hypertrophy. Am J Cardiol 1994;74:714-9.

12. Casale PN, Devereux RB, Kligfield P, Eisenberg RR, Miller DH, Chaudhary BS, et al. Electrocardiographic detection of left ventricular hypertrophy: development and prospective validation of improved criteria. J Am Coll Cardiol 1985;6:572-80.

13. Hancock EW, Deal BJ, Mirvis DM, Okin P, Kligfield P, Gettes LS. AHA/ACCF/HRS recommendations for the standardization and interpretation of the electrocardiogram: part V: electrocardiogram changes associated with cardiac chamber hypertrophy: a scientific statement from the American Heart Association Electrocardiography and Arrhythmias Committee, Council on Clinical Cardiology; the American College of Cardiology Foundation; and the Heart Rhythm Society. Endorsed by the International Society for Computerized Electrocardiology. J Am Coll Cardiol 2009;53:992-1002.

14. Sokolow M, Lyon TP. The ventricular complex in right ventricular hypertrophy as obtained by unipolar precordial and limb leads. Am Heart J 1949;37:161-86.

15. Okin PM, Roman MJ, Devereux RB, Kohsaka S. Electrocardiographic identification of increased left ventricular mass by simple voltage-duration products. J Am Coll Cardiol 1995; 25: 417-23.

16. Devereux RB, Dahlof B, Levy D, Pfeffer MA. Comparison of enalapril versus nifedipine to decrease left ventricular hypertrophy in systemic hypertension (the PRESERVE trial). Am J Cardiol 1996; 78: 61-5.

17. Peguero JG, Lo Presti S, Perez J, Issa O, Brenes JC, Tolentino A. Electrocardiographic Criteria for the Diagnosis of Left Ventricular Hypertrophy. 2017; 69(13): 1694-703

18. Bacharova L, Ugander M. Left ventricular hypertrophy: the relationship between the electrocardiogram and cardiovascular magnetic resonance imaging. Ann Noninvasive Electrocardiol 2014;19:524-33.

19. Casale PN, Devereux RB, Alonso DR, Campo E, Kligfield P. Improved sex-specific criteria of left ventricular hypertrophy for clinical and computer interpretation of electrocardiograms: validation with autopsy findings. Circulation 1987;75:565-72.

20. Angeli F, Verdecchia P, Angeli E, Poeta F, Sardone M, Bentivoglio M, et al. Day-today variability of electrocardiographic diagnosis of left ventricular hypertrophy in hypertensive patients. Influence of electrode placement. J Cardiovasc Med 2006;7:812-6.

21. Palmieri V, Dahlöf B, DeQuattro V, Sharpe N, Bella JN, de Simone G, et al. Reliability of echocardiographic assessment of left ventricular structure and function: the PRESERVE study. Prospective Randomized Study Evaluating Regression of Ventricular Enlargement. J Am Coll Cardiol 1999;34:1625-32.

22. Bacharova L. Electrocardiography-left ventricular mass discrepancies in left ventricular hypertrophy: electrocardiography imperfection or beyond perfection? J Electrocardiol 2009;42: 593-6.

23. Narayanan K, Reinier K, Teodorescu C, Uy-Evanado A, Chugh H, Gunson K, et al. Electrocardiographic versus echocardiographic left ventricular hypertrophy and sudden cardiac arrest in the community. Heart Rhythm 2014;11: 1040-6. 